M. BENLLIURE ARANA: PROYECTO de ACUARIUM PARA SEVILLA.

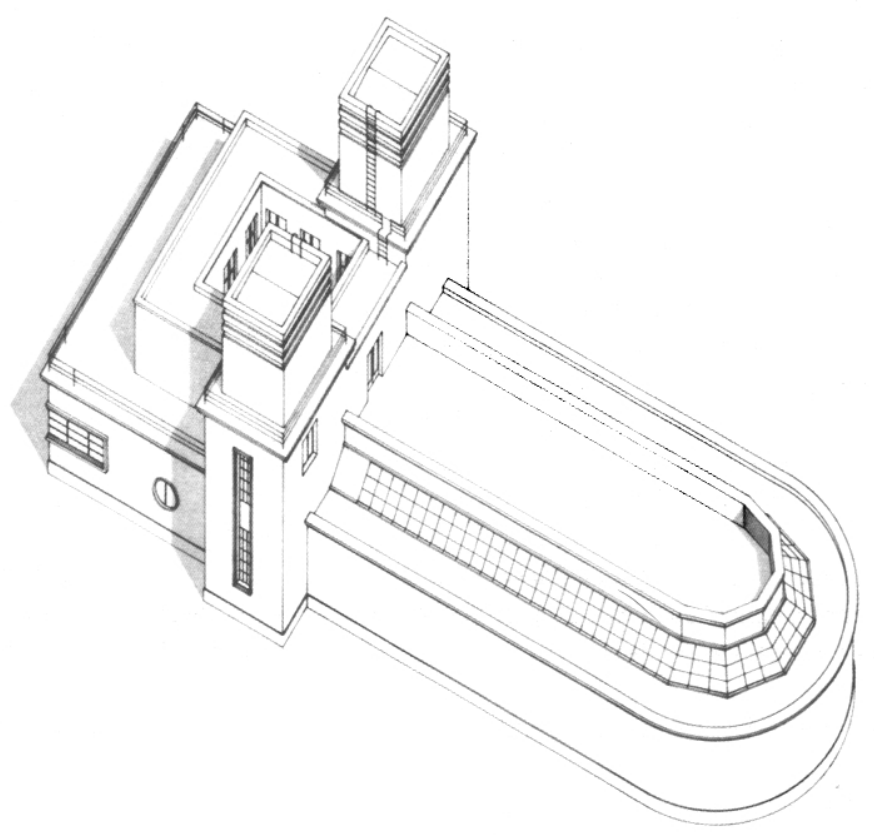

\title{
A propósito de un catálogo de arquitectura racionalista en Sevilla (1926-1942)
}

José María Jiménez Ramón

Dr. Arquitecto

Dpto. de Expresión

Gráfica Arquitectónica.

Universidad de Sevilla
Cuando Wolfang Pehnt redacta el prólogo de su tratado sobre la arquitectura expresionista y trata de explicar el significado de su título, tiene que acabar reconociendo que la etiqueta expresionista que emplea en el libro únicamente implica que los diseños y edificios que en él se incluyen presentan una similitud entre sí mayor que con otros diseños y edificios. Para justificarse afirma a continuación que exigir una correspondencia absoluta entre la cosa y el término es pedir demasiado a cualquier denominación estilística...o, en general, a cualquier término.' Aparte de la razonable disgresión lingüística, lo más importante de esta definición de Penht, es la consideración que asume de que lo que realmente implica la definición del término es 
la selección del material que usando dicho término se haga. $O$, visto a la inversa, la previa agrupación de un determinado material arquitectónico definirá, por analogías e interrelaciones, el significado del término que se use para etiquetarla. Por otra parte la implicación del sujeto que hace la selección confiere un inevitable grado de subjetivismo a la propia definición que la selección genera. En cualquier caso, el catálogo, entendido como base de datos, tiene un papel fundamental en el desarrollo posterior de la investigación y, en consecuencia, en la generación de sus distintas hipótesis interpretativas y conclusiones.

Un problema similar, si no mayor, se presenta cuando tratamos de definir el término racionalismo aplicado a la arquitectura de nuestro período. Este problema se agudiza aún más si con dicha definición tenemos que referirnos a un conjunto de proyectos y edificios que forman una serie tan heterogénea y dispar como la que compone el catálogo del que esta breve reseña pretende dar noticia. Este catálogo ha sido recientemente presentado como segunda parte de mi Tesis Doctoral sobre Gabriel Lupiáñez Gely y la arquitectura racionalista en Sevilla (1926-1942).

Cuando, allá por 1984, iniciaba las tareas investigadoras conducentes a dicha Tesis, a la vista del singularmente negativo panorama histórico que presentaba nuestra ciudad en el marco de estudio prefijado, no parecía razonable esperar que se pudiera encontrar en Sevilla un número importante de edificios racionalistas del período. Abundando en dicha idea, la arquitectura objeto de nuestro interés distaba mucho de estar, por tanto, no sólo enmarcada o perfilada, sino que incluso podía plantearse a priori su probable incapacidad para generar, en conjunto, un material de trabajo suficientemente extenso y cualitativamente capaz de trascender la predibujada idea de una mera anécdota superficial en un contexto culturalmente atrasado. Sin embargo, partiendo de la hipótesis de que, en mayor o menor medida, un fenómeno tan ineludible como la irrupción de la modernidad, entendida en sentido general, como un fenómeno social, o cultural si se quiere, en la tercera y cuarta décadas de nuestro siglo, tuvo que producir necesariamente sus efectos también en el campo de lo arquitectónico, resultaba enormemente atrayente sumergirse en el período y comprobar cuál fue la realidad de este proceso. Por otra parte, se conservan de hecho signos en la ciudad (edificios) que permitían vislumbrar que efectivamente algo hubo. Para gran parte de los arquitectos que hoy ejercen la profesión en esta ciudad, entre los que evidentemente me incluyo, los escasos ejemplos que tuvieron la suerte de pasar del papel a la realidad construída y la aún mayor fortuna de sobrevivir hasta nuestros días, constituyen un patrimonio propio y se han convertido en objetos con una componente afectiva innegable, que ocupan un hueco en nuestros archivos de memoria. Y ello pese a estar sus estampas degradadas, en muchos casos y durante mucho tiempo, por el olvido y la incomprensión.

En los primeros acercamientos al problema y siempre a partir de lo oído y leído, tampoco aparecía a priori con claridad una figura suficientemente perfilada sobre las demás como para elaborar a partir de ella un referente conceptual para todo el ciclo, aunque el curso de los trabajos me ha llevado finalmente a trabajar en este sentido alrededor de la figura de Gabriel Lupiáñez. Es verdad que uno de los principales motivos para mi incursión en este estudio fue el temprano e importante descubrimiento de la relevancia que en el marco nacional llega a tener la fecha del proyecto del Mercado de la Puerta de la Carne: diciembre de 1926, obra de este arquitecto. También es verdad que, desde el primer momento, llevado por la necesidad de acotar temporalmente un proceso difuso (y por tanto difícilmente acotable), acudí de nuevo a esta figura histórica: su azarosa vida concluye tempranamente por causa de su enfermedad en 1942, por lo que siendo el primero podía también servir de referencia para cerrar el proceso en una fecha adecuada: pasados un cierto numero de años del momento álgido nacional e internacional, y pasados igualmente los más graves y tristes episodios que jalonan nuestra historia española contemporánea, permitiendo realizar un apunte sobre la trascendencia de estos hechos nacionales en la continuidad de ciertas búsquedas arquitectónicas locales.

Sin embargo esta doble referencia primera a la figura de Lupiáñez no implicaba en modo alguno más que un reconocimiento ( $y$ de hecho una utilización operativa) de su oportunidad histórica, pero en ningún caso una diferenciación cualitativa como la posteriormente llevada a cabo. Muy al contrario, de acuerdo con todos los antecedentes hasta aquí expuestos, el trabajo optó desde el principio por una construcción completa desde cero, planteando directamente un estudio exhaustivo de toda la arquitectura racionalista sevillana. Así, en 1984, cuando se presenta en la E.T.S.A.S. la propuesta de redacción de la Tesis Doctoral, figura aún con el título genérico de: ARQUITECTURA RACIONALISTA EN SEVILLA, 19261942. Este planteamiento genérico, el único coherente en su momento a mi modesto entender, partía sin embargo de dos malentendidos que lo hacían, en la práctica, casi inviable: el infradimensionado cálculo sobre la extensión del fenómeno racionalista sevillano, por un lado, y la hipertrofiada estimación de mis propias fuerzas para llevar a cabo la tarea, por otro. Como el discurrir de los trabajos puso finalmente de manifiesto, la tarea de identificar y analizar exhaustivamente la totalidad de los aspectos, las obras, los autores de dicho fenómeno, partiendo prácticamente de la nada, era un objetivo hiperdimensionado del que toda la Tesis no representa, a la postre, más que una pequeña parte. No obstante, esta definitiva limitación de la extensión prefijada no es sólo, ni siquiera principalmente, fruto directo de dicho incumplimiento, sino de la progresiva aparición de factores cualitativos en principio no previstos, gracias a lo cuales la figura de Gabriel Lupiáñez, frente al resto, fue ganando en nitidez biográfica, oportunidad histórica y profundidad conceptual.

Como no hay mal que por bien no venga, la desmesurada amplitud del objetivo trazado al principio tuvo como consecuencia positiva el acopio de un impor-
I. Pehht, Wolfgang, La arquitectura expresionista. Ed. Gustavo Gili, Barcelona, 1975:8 


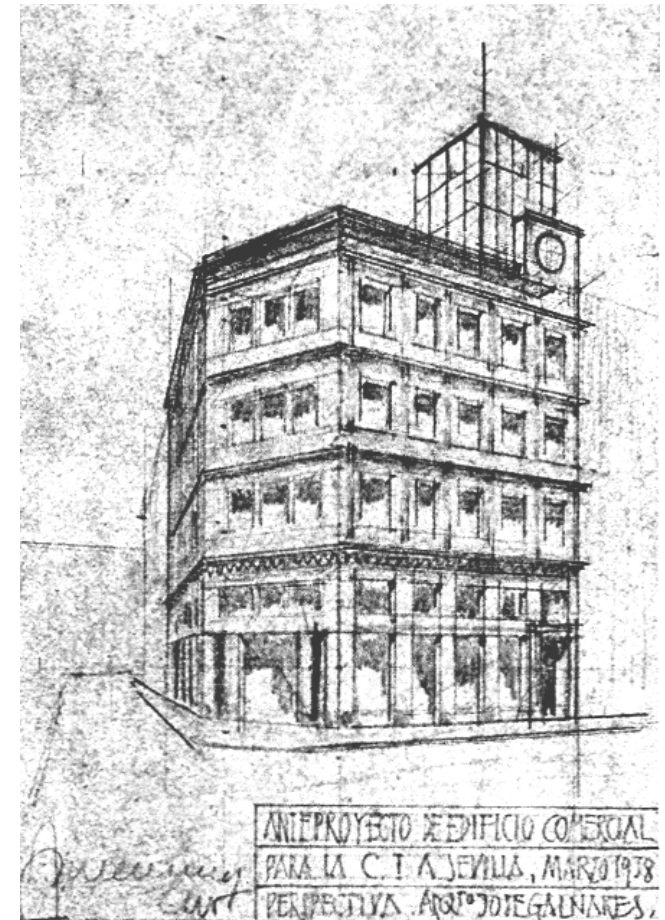

tante cúmulo de documentación sobre el fenómeno, documentación que espero sea de utilidad para cualquier estudio global o parcial que del tema quiera realizarse en el futuro. En efecto, la tarea prioritaria en un principio era la elaboración de la más completa base de datos posible, consecuencia fundamental de la reflexión metodológica apuntada. Esta base de datos llegó a constituir finalmente una relación exhaustiva de la arquitectura racionalista construida o proyectada en Sevilla, relación que constituye el "Catálogo de la arquitectura racionalista en Sevilla" a que nos estamos refiriendo.

El planteamiento de este catálogo fue desde un principio el más aséptico e imparcial posible. El objetivo era no introducir tergiversación alguna, por atreverme a intencionarla prematuramente, en la progresiva recopilación y selección del material que habría de representar la base fundamental de toda la tesis. Dado que la documentación bibliográfica sobre el tema era muy escasa y no carente de multitud de imprecisiones y errores, había que ir a las propias fuentes documentales para conseguir la información necesaria. Con esta intención se han llegado a revisar, expediente por expediente, todos los archivos, públicos y particulares, que pudieran ser de alguna transcendencia. Así, se inspeccionaron todos los legajos del marco temporal fijado (1926-1942) que se encuentran en el Archivo Administrativo Municipal de SeviIla, tanto en el apartado de Obras de Particulares como en los de Obras Públicas y de Construcciones y Reconstrucciones, así como las relaciones de obras de dicho periodo visadas y consignadas en el Libro de Registro del entonces Colegio Oficial de Arquitectos de Andalucía, Canarias y Marruecos, aunque en este caso, lamentablemente, no se conserva documentación gráfica alguna. que el archivo de Lupiáñez y Arévalo lo tuvo en su poder hasta que se deshizo de él por necesidades de espacio en su oficina. Fue quemado.
También se ha revisado la Sección de Educación y Ciencia del Archivo General del Estado, para todo el material referente a construcciones escolares. Se han estudiado igualmente, de manera exhaustiva, los archivos particulares de D. José Galnares Sagastizábal, D. Joaquín Díaz Langa, D. José Granados de la Vega, D. Rodrigo de Medina Benjumea y parte del archivo de D. Antonio Delgado Roig. Desgraciadamente, el que a la postre habría sido sin duda el archivo fundamental, el de Gabriel Lupiáñez y Rafael Arévalo, se ha perdido inexorablemente y nunca se podrá saber lo que contenía ni, en consecuencia, valorar con exactitud la importancia de su destrucción². Sólo la revisión de los archivos de la Diputación Provincial de Sevilla, a la que permaneció ligado profesionalmente Lupiáñez durante toda su vida, ha permitido llenar mínimamente ese vacío con la aportación de algunas precisiones biográficas $y$, sobre todo, con la recuperación del expediente íntegro, con memoria y planos originales, correspondiente al proyecto para el Instituto Anatómico, documento inestimable cuya trascendencia justifica uno de los capítulos fundamentales de todo el estudio. Por último, se han revisado igualmente los archivos municipales, en unos casos ordenados y en otros no, de los distintos pueblos de la provincia de Sevilla en los que se sospechaba la presencia de obras de alguno de los arquitectos estudiados.

Volviendo al tema con el que empezamos, el referido a la selección del material de estudio, cuando nos enfrentamos con el problema nos encontramos en una tesitura que tiene algo de círculo vicioso, algo así como una nueva versión del insoluble problema de la precedencia del huevo o la gallina. Si preestablecemos una categoría conceptual, formal o supraformal, que defina con precisión y exhaustividad las condiciones que han de cumplir los diseños para poder ser clasificados en ella y con esta definición nos lanzamos a la búsqueda de cuales pueden ser aquellos ejemplos que las cumplan, tendremos la certeza de delimitar rigurosamente nuestro universo de estudio. Pero a cambio de esta, quizá esteril, certeza, habremos dejado en el camino (a fin de cuentas el proceso investigador no es otra cosa que un camino) toda una serie de aportaciones que hubieran podido enriquecer muestro conocimiento de la actividad creadora de un período especialmente significativo para el entendimiento de nuestra coyuntura presente. Si por el contrario descartamos cualquier definición apriorística, en el caso de esto fuera posible, nos encontraríamos con que el universo de estudio no tendría restricción alguna y, en consecuencia, sería obsoleto por su propia indefinición y, por ello, difícilmente podría servir como base de trabajo para extraer alguna conclusión.

En esta diatriba no queda otra alternativa que optar por una solución intermedia que parta de una definición previa lo suficientemente amplia como para que mediante su aplicación se pueda seleccionar un material, una base de datos, sobre la que aplicar distintas angulaciones analíticas y determinar, a través de ellas, el significado o significados que su conjunto, como tal, encierra.

En el entendimiento de que mi trabajo tiene el carácter de primera aportación de un material que pudiéramos casi denominar inexplorado y asumiendo la inevitable subjetividad en la selección, se ha preferido 
pecar de laxitud, antes que de intransigencia, en el establecimiento de las condiciones que habían de regir aquella. Así, aún a riesgo de incurrir en algunos casos en una improcedente incorporación, se eludía el problema, más grave, de privar, a futuros investigadores que pudieran recurrir a este trabajo como elemento de consulta, de un material de farragosa recopilación que pudiera adquirir un significado que, a mí y ahora, pueda escapárseme.

El estricto cumplimiento de este planteamiento desembocaría necesariamente en la disolución de las obras significativas en un magma indiferenciado de obras de escasa relevancia, pero incorporadas en virtud del principio de base antes expuesto. Para evitar este inconveniente y no transgredir el planteamiento establecido, se ha tomado la determinación de hacer una clasificación básica de los distintos proyectos y obras en dos categorías diferenciadas. Una corresponde a los edificios que pudiéramos considerar de escasa transcendencia, bien por su escasa envergadura o bien por su relativo, aunque presente en cualquier caso, acercamiento a la modernidad. La otra categoría corresponde al resto de los edificios. En correspondencia con esta clasificación se ha tratado la presentación de los distintos proyectos o edificios de dos formas distintas. Así, mientras que a los primeros sólo se les dedica un espacio restringido, de modo que varios de ellos comparten una misma página, reseñando todos sus datos documentales e incluyendo algunos de los gráficos que los definen, a los segundos, que, a la postre son la mayoría, se les trata ampliamente reproduciendo, en cuantas páginas se ha precisado, todos los gráficos que componen el proyecto así como fotografías, en su caso, y haciendo un primer análisis que garantizara un detenerse en ellos para apropiarse, al menos en primera instancia, de su sentido. Como incluso con esta clasificación el resultado del catálogo podía seguir pecando de indiferenciado, se tomó la determinación de implementar la documentación gráfica de aquellos proyectos que se consideraron más importantes mediante la construcción ex-profeso de perspectivas que permitieran, amén de su puesta en valor, la mejor comprensión de su volumetría. Con esta serie de determinaciones se pretende que el catálogo resulte, de algún modo, intencionado críticamente.

A fin de sentar las bases para posibles estudios posteriores sobre el tema y a la vista de la gran cantidad de errores e imprecisiones que en la datación de los edificios se ha encontrado en la escasa bibliografía existente, se ha considerado una tarea primordial la correcta documentación de los distintos expedientes.

En consecuencia, se ha cuidado especialmente de la exactitud de los datos que figuran en la ficha de cada edificio. Las fechas que en ellas se recogen están extraídas de documentos palpables: memorias o planos de los proyectos, solicitudes de licencias municipales, certificados de fin de obra, libro de registro del Colegio de Arquitectos, etc. Cuando alguna fecha no reúne esta característica o bien se omite, que es lo más habitual, o se cita la procedencia de la datación, en caso de existir alguna bibliografía al respecto o, en aquellos casos en que haya indicios pero no documentos, se añade una interrogación a la fecha que se propone.

A fin de facilitar la utilización autónoma del catálogo se ha optado por establecer una denominación de cada expediente con una matrícula compuesta de dos letras y cuatro números. Las dos letras son las iniciales del apellido arquitecto, o de uno de ellos si se trata de una colaboración, los dos números siguientes corresponden a los dos últimos dígitos del año de su proyecto y los dos últimos se destinan a una numeración ordinal de los distintos proyectos realizados en el mismo año por el(los) mismo(s) arquitecto(s).

El hecho de haber elegido las iniciales de uno u otro arquitecto, en los casos de autoría compartida, no debe ser entendido más que como un convenio, nunca como una atribución. La atribución concreta de cada proyecto se hace en la ficha de datos en la casilla correspondiente a "arquitecto:".

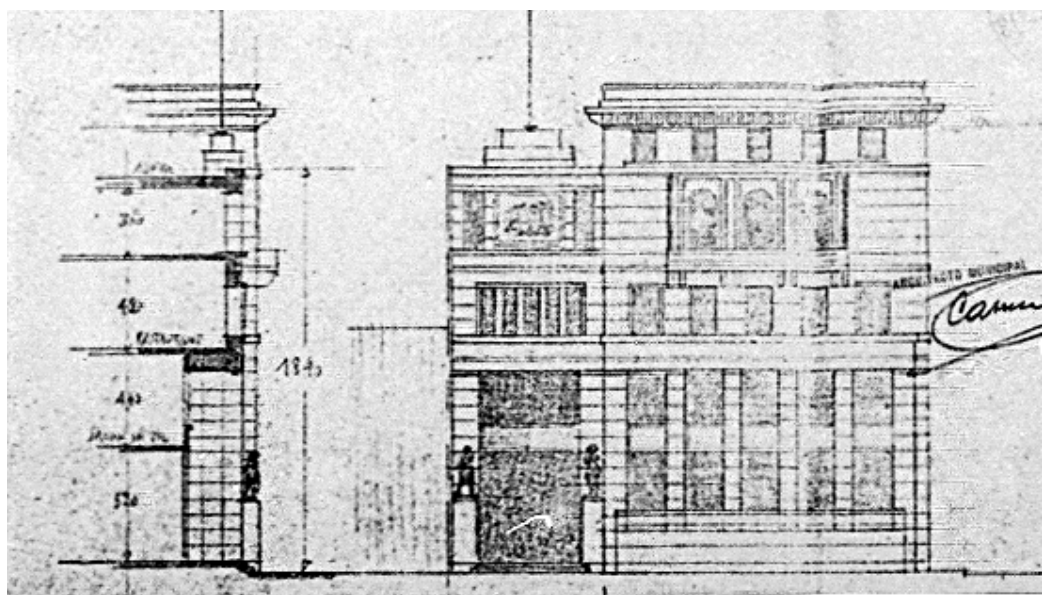

Una vez establecido el convenio de matriculación que hemos expuesto, la ordenación del catálogo se hace por riguroso orden alfanumérico. Como las obras menores están obligadas a compartir página, a razón de tres por cada una de éstas, mientras que el resto de las obras ocupan un mínimo de dos, es imposible aplicar para ellas el criterio de ordenación antes fijado, por lo que se adopta el criterio de agrupar, las de cada arquitecto, al final del apartado correspondiente a cada uno de ellos.

A fin de ilustrar los contenidos que se han expuesto, se incluye la reproducción de uno de los ejemplos de cada una de las dos categorías antes reseñada. Se ha elegido la primera que, de las 213 que componen la totalidad, aparece en el catálogo conforme a la ordenación referida. Así mismo se reproduce una de las páginas de las que podríamos denominar "obras menores". 


\begin{tabular}{|c|c|c|c|c|}
\hline 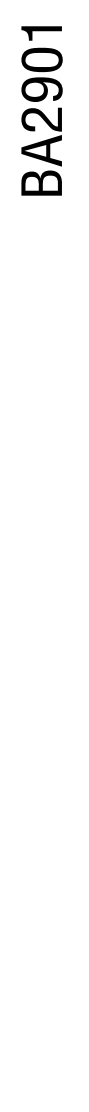 & 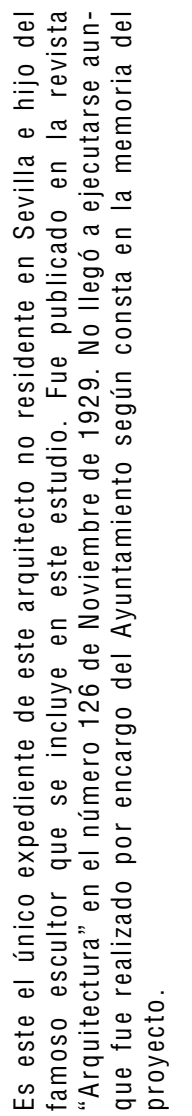 & 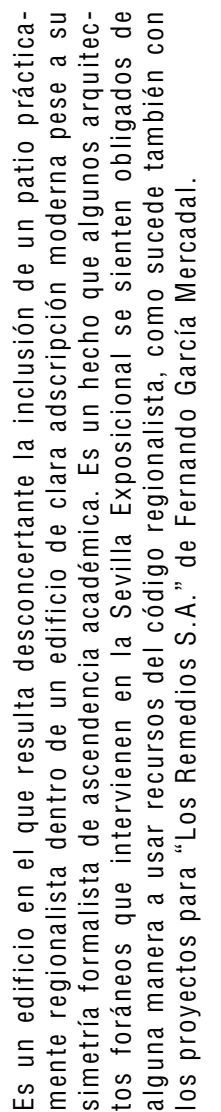 & 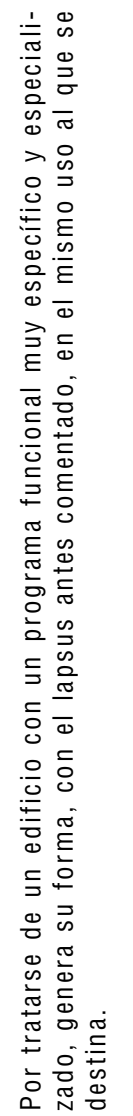 & 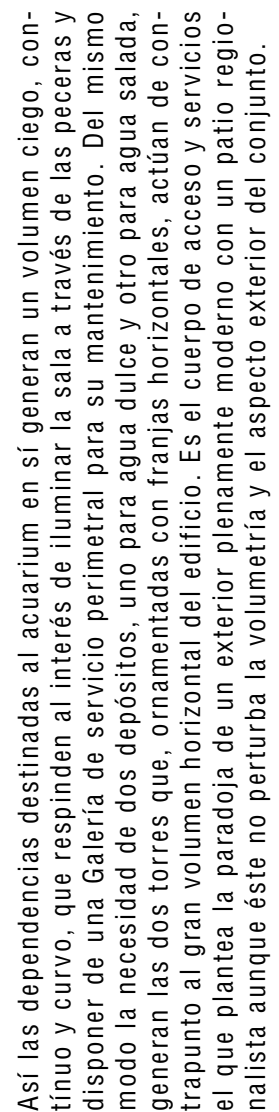 \\
\hline
\end{tabular}




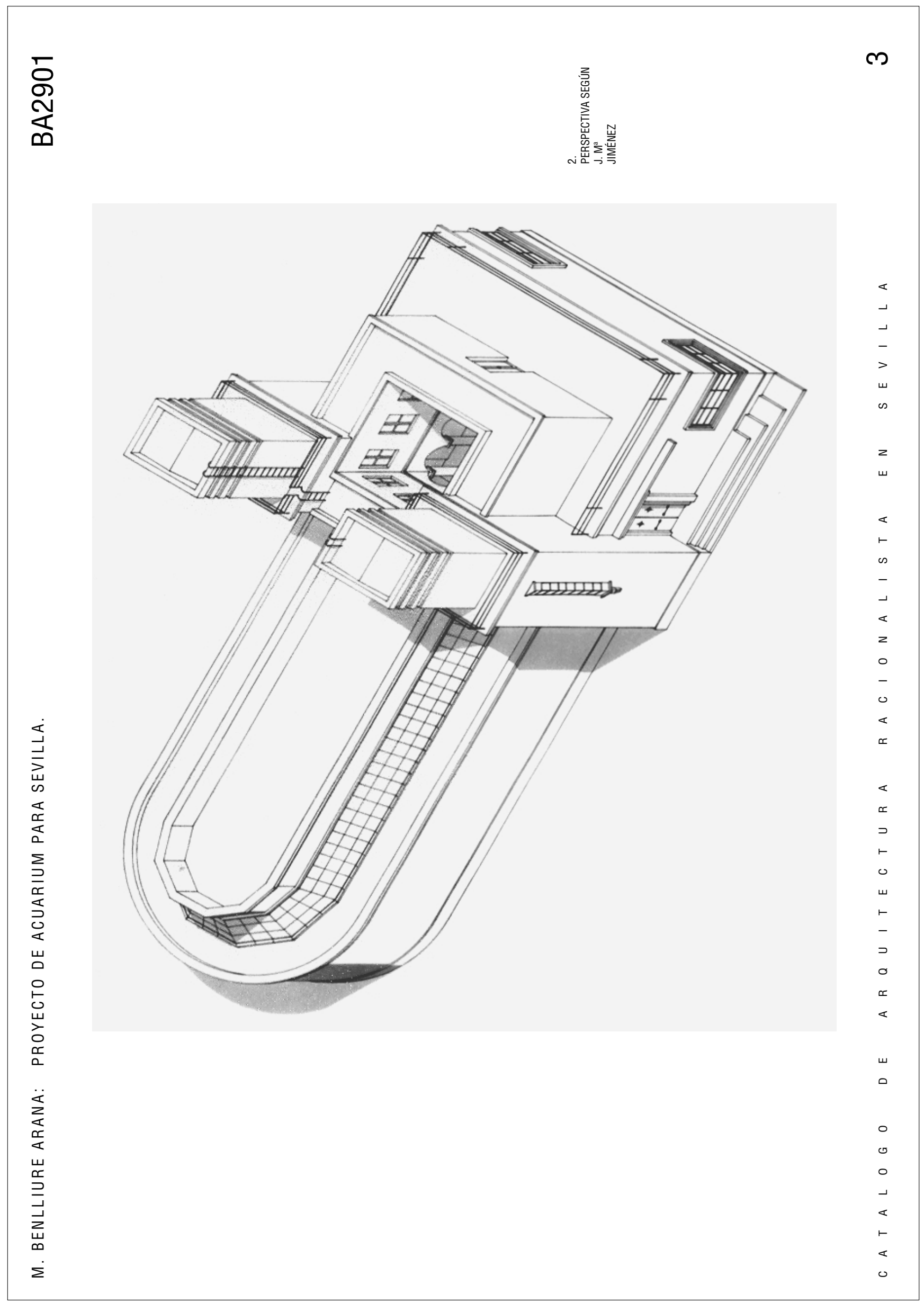


产

m.

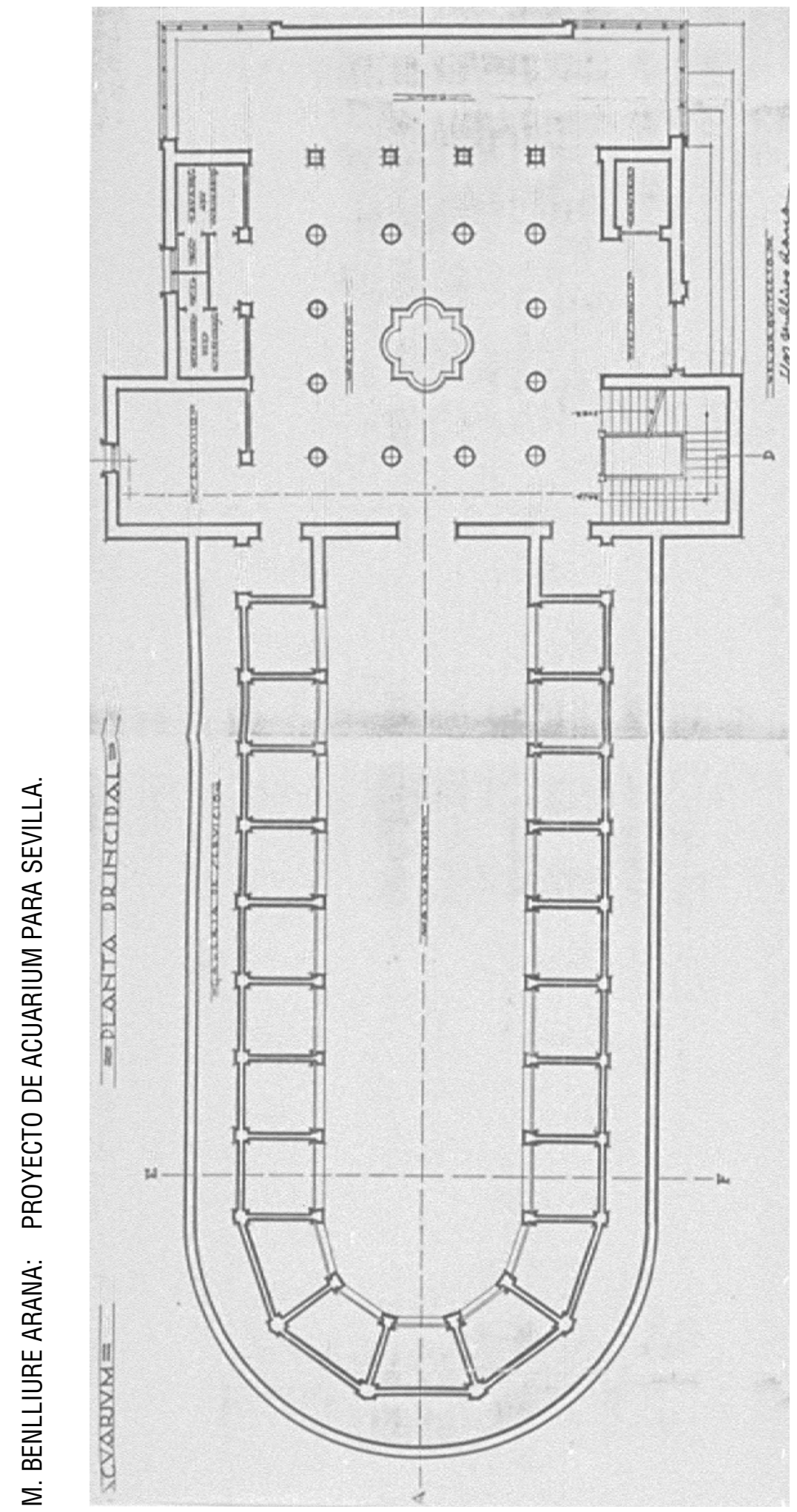


ธั่

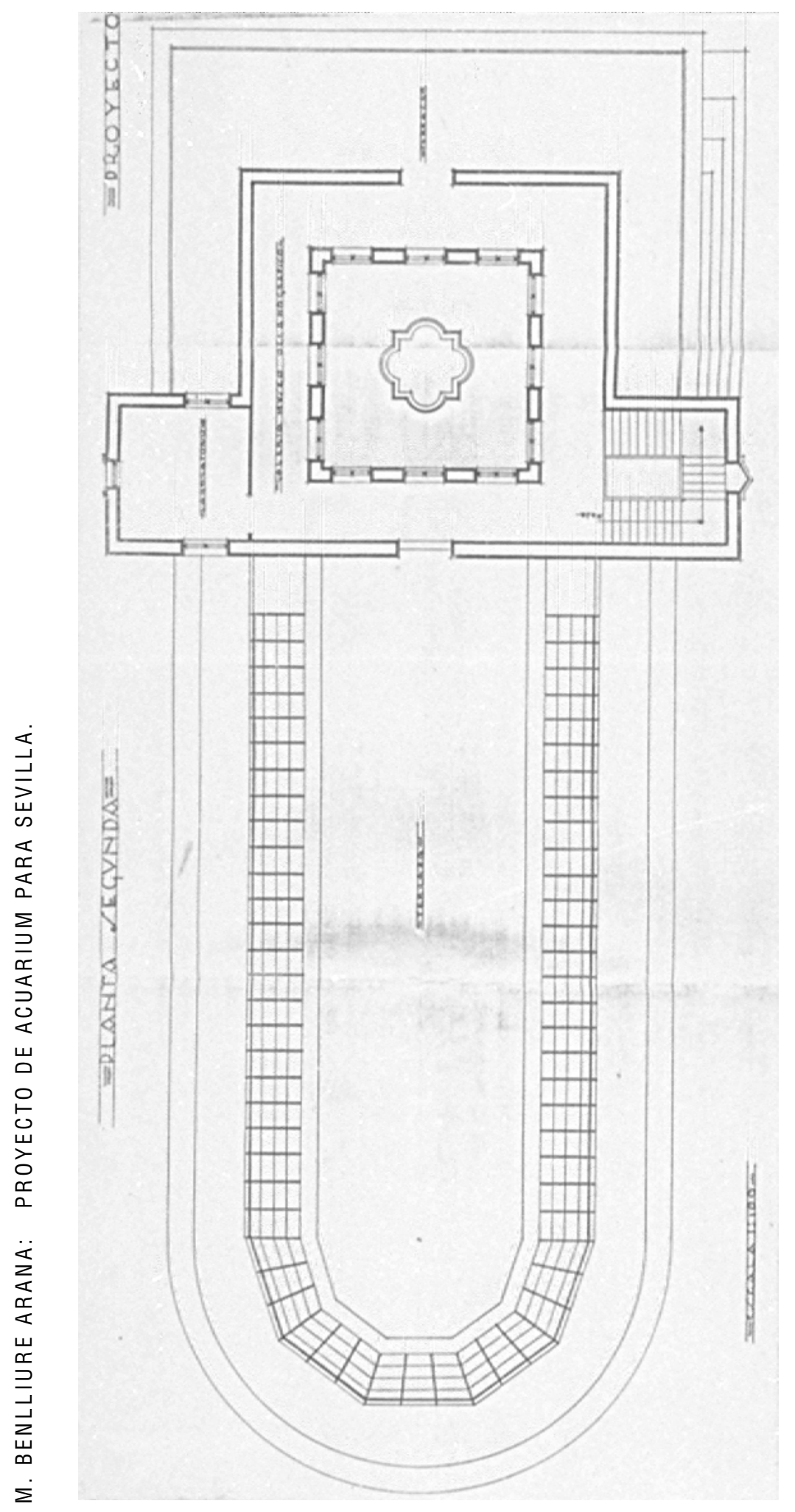




\section{ర్వ్య}
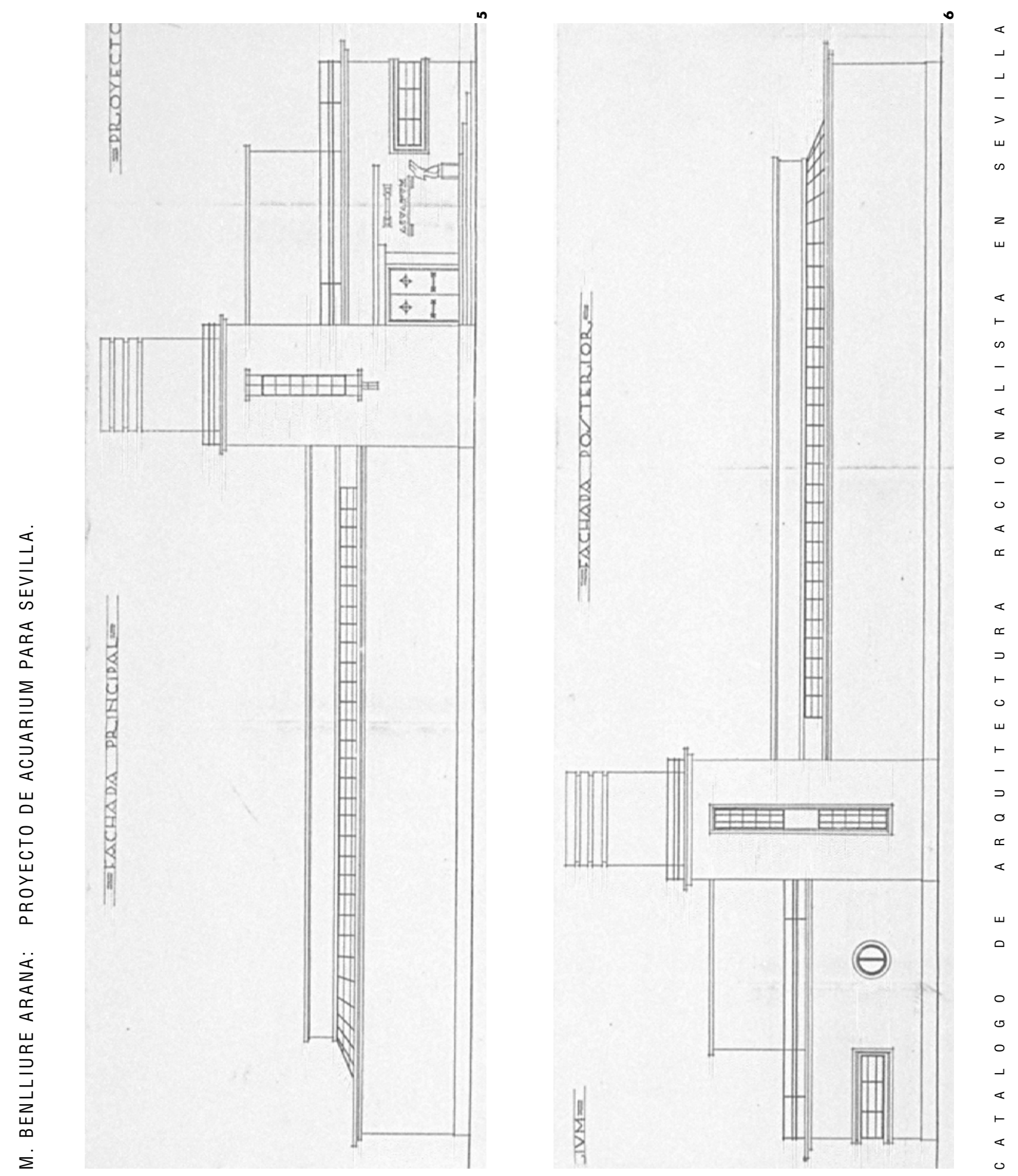
๖̊

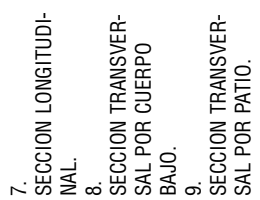

$N$
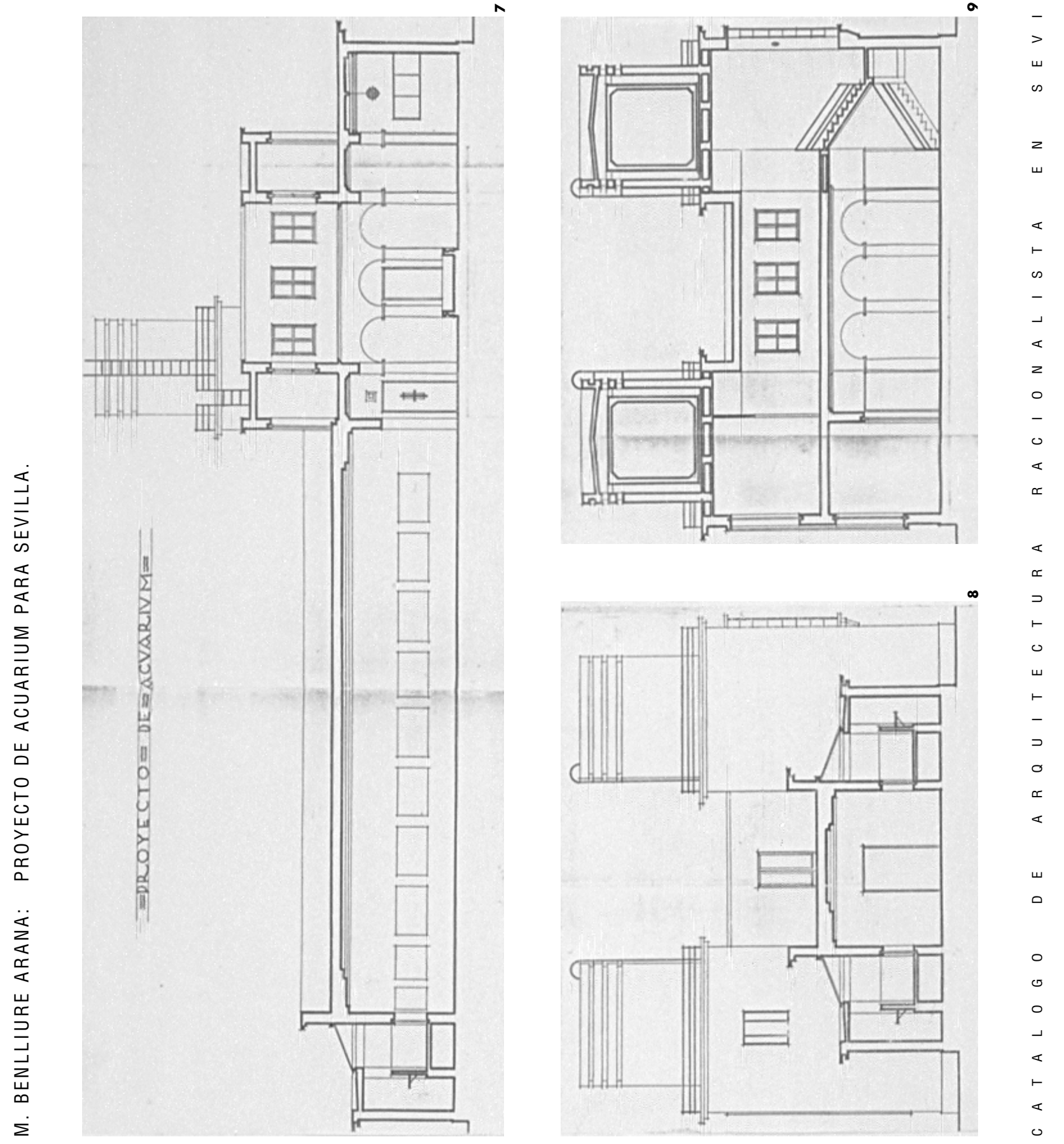


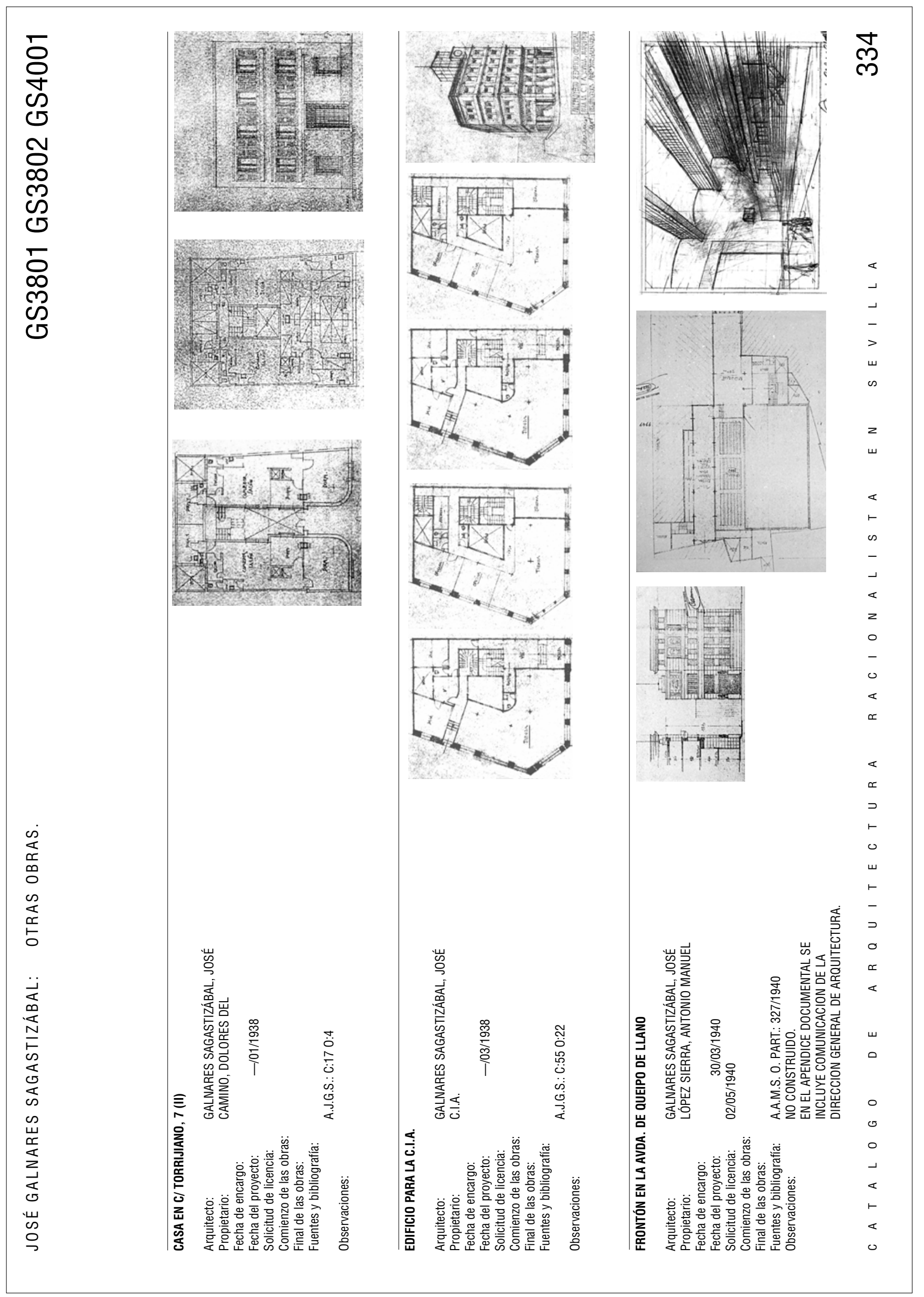

